\title{
Baclofen in the treatment of alcohol dependence with or without liver disease: multisite, randomised, double-blind, placebo-controlled trial
}

Kirsten C. Morley, Andrew Baillie, Isabel Fraser, Ainsley Furneaux-Bate, Glenys Dore, Michael Roberts, Ahmed Abdalla, Nghi Phung and Paul S. Haber

\section{Background}

There are no available medications for the management of alcohol dependence for patients with alcoholic liver disease (ALD).
Aims
To conduct a multisite, double blind, placebo-controlled, ran- domised clinical trial of baclofen in the treatment of alcohol dependence, with or without liver disease (trial registration: ClinicalTrials.gov, NCT01711125)

\section{Method}
Patients $(n=104)$ were randomised to placebo, baclofen $30 \mathrm{mg} /$ day or $75 \mathrm{mg} /$ day for 12 weeks. Primary outcomes included survival time to lapse (any drinking), relapse ( $\geq 5$ drinks per day in men and $\geq 4$ in women), and the composite outcome of drinks per drinking day, number of heavy drinking days, and percentage days abstinent.

Worldwide, harmful use of alcohol is responsible for $5.9 \%$ of al deaths and is a causal factor in more than 200 disease and injury conditions. ${ }^{1}$ Alcoholic liver disease (ALD) is one of the leading causes of alcohol-related death. ${ }^{2}$ Abstinence from alcohol is crucial to reducing morbidity and mortality associated with $\mathrm{ALD}^{3}$ making treatment of this group a priority. There are currently no approved treatments for alcohol-use disorders for those with advanced liver disease. Current pharmacotherapies are limited by potential for hepatotoxicity in patients with significant liver disease (for a review see Addolorato et al). ${ }^{4}$ Baclofen, a selective gamma-aminobutyric acid $(\mathrm{GABA})_{\mathrm{B}}$ receptor agonist with minimal liver metabolism, is emerging as a potential treatment for alcohol dependence with few reported hepatic side-effects. Preclinical studies have demonstrated baclofen to diminish selfadministration of alcohol, maintenance and reinstatement of alcohol-drinking behaviour. ${ }^{5,6}$ The clinical effectiveness of baclofen in reducing measures of alcohol dependence in patients with ALD has been demonstrated via one double-blind randomised controlled trial (RCT) of 84 patients. ${ }^{7}$ There has since been expanded use of baclofen in the treatment of alcohol dependence, independent of ALD, with a large proportion in Europe being initiated in primary care. ${ }^{8}$ Nonetheless, there is controversy in the field given that, among the high-quality trials in the literature, the results for lowhigh dose regimens of baclofen are mixed (for example see ${ }^{9-14}$ ). The widespread use of baclofen in the community is still beyond the evidence base.

The baclofen in the treatment of alcohol liver disease (BacALD) protocol ${ }^{15}$ was thus developed to further investigate baclofen treatment for patients who are alcohol dependent including those with liver disease. The current study aims to directly evaluate the efficacy of two doses of baclofen $(30 \mathrm{mg} /$ day and $75 \mathrm{mg}$ /day) $v$. placebo in a randomised, placebo-controlled double-blind study (trial registration: ClinicalTrials.gov, NCT01711125). We hypothesise that

\section{Results}

There was a significant effect of baclofen (composite groups) on time to lapse $\left(\chi^{2}=6.44, P<0.05\right.$, Cohen's $\left.d=0.56\right)$ and relapse $\left(\chi^{2}\right.$ $=4.62, P<0.05, d=0.52$ ). A significant treatment effect of baclofen was observed for percentage days abstinent (placebo 43\%, baclofen $30 \mathrm{mg}$ 69\%, baclofen $75 \mathrm{mg} 65 \%$; $P<0.05$ ). There was one serious adverse event (overdose) directly related to medication (75 mg).

\section{Conclusions}

Baclofen may be an effective treatment option for patients with ALD. However, given the profile of adverse events, the role for this medication might be best limited to specialist services.

\section{Declaration of interest}

None.

\section{Copyright and usage}

(c) The Royal College of Psychiatrists 2018. patients treated with baclofen will (a) significantly reduce their drinking compared with placebo, (as measured by the days abstinent, time to lapse and relapse, number of drinks per drinking day, number of heavy drinking days), and (b) severity of dependence and craving along with measures of anxiety, depression, stress and clinical markers of liver injury will be significantly reduced in individuals treated with baclofen compared with those on placebo.

\section{Method}

The detailed methodology and study protocol are described in a separate protocol paper. ${ }^{15}$

\section{Study design}

The study was a 12 -week randomised, double-blind, placebo-controlled trial in which participants who were alcohol dependent, with or without liver disease received $10 \mathrm{mg}$ or $25 \mathrm{mg}$ of baclofen three times a day, or matching placebo for a 12 -week period. The study was conducted over a 36-month period at three sites (Royal Prince Alfred Hospital, North Shore Hospital and Westmead Hospital) in Australia between 2013 and 2016. The study was approved by the Human Ethics Review Committee of the Sydney Local Health District, Northern Sydney Local Health District and South Western Sydney Local Health District (X11-0154). The trial was registered in the Clinical Trials Registry (NCT01711125). Initially the trial was limited to patients with ALD; however, the protocol was amended to include a parallel non-ALD group given emerging controversy in the literature about the use of baclofen in patients who are alcohol dependent but without ALD.

The study involved off-label use of a registered medication in Australia and approval was given under the clinical trial notification 
scheme of the Therapeutics Goods Administration (2013/0060). An independent data safety and monitoring board provided oversight and monitoring to ensure the safety of participants and validity and integrity of the trial. The chief trial physician (P.S.H.) reported serious or unexpected adverse events to the lead hospital ethics review committee and to the data safety and monitoring board for review.

\section{Participants}

Potential male and female participants were identified by treating clinicians at the out-patient drug and alcohol unit, liver clinic or who had responded to online advertising. We accepted reduction or abstinence as participant treatment goals. Patients with alcohol dependence were stratified according to presence or absence of ALD.

Inclusion criteria were (a) alcohol dependence according to the ICD-10 criteria; ${ }^{16}$ (b) age 18-75; (c) adequate cognition and English language skills to give valid consent and complete research interviews; (d) willingness to give written informed consent; (e) abstinence from alcohol for between 3 and 21 days before enrolment; (f) resolution of any clinically evident alcohol withdrawal (on the Clinical Institute Withdrawal Assessment for alcohol (CIWA$\mathrm{Ar}){ }^{17}$ and $(\mathrm{g})$ less than $48 \mathrm{~h}$ after ceasing any diazepam required for withdrawal management.

For stratification, ALD was defined as the presence of symptoms and/or signs referable to liver disease or its complications with or without cirrhosis, in which alcohol use is considered to play a major aetiological role. Alcohol use will have exceeded an average of $60 \mathrm{~g} /$ day in women and $80 \mathrm{~g} /$ day in men for $>10$ years. If other cofactors such as chronic hepatitis $\mathrm{C}$ are present, a significant contribution of alcohol to liver disease will be considered present if a period of supervised abstinence (for example in hospital) leads to a $\geq 50 \%$ improvement in liver enzymes.

Exclusion criteria were: (a) active major mental disorder associated with psychosis or significant suicide risk, (b) pregnancy or lactation, (c) concurrent use of any psychotropic medication other than antidepressants (provided these are taken at stable doses for at least 2 months); (d) unstable substance use; (e) clinical evidence of persisting hepatic encephalopathy (drowsiness, sleep inversion or asterixis); (f) pending incarceration; (g) lack of stable housing; (h) peptic ulcer; and (i) unstable diabetes mellitus.

\section{Study procedures}

The treatment procedure and frequency of assessments were explained to all eligible individuals and a study information sheet was provided. Participants were informed about the study objectives, the nature of adherence therapy, the profile of baclofen and that the medication they would receive would be chosen at random. They were informed that they would not be withdrawn from the programme if they relapsed or failed to comply with the medication and that they could chose to leave the programme at any time. Screening procedures included a medical history and physical examination. Laboratory evaluations included liver tests and biochemistry, urinalysis, urine toxicology and human chorionic gonadotropin in women. Patients who had significant withdrawal symptoms with a CIWA- $\mathrm{Ar}^{17}$ score of $>10$ were referred for detoxification treatment according to local detoxification guidelines. If eligible, participants were then scheduled for the enrolment visit (baseline interviews and initial treatment) within 1 week.

Assertive follow-up involved several telephone reminders, text messages and/or mailed reminder letters for missed appointments. All attempts were made to obtain drinking information (via phone or medical records) during the study period regardless of medication adherence or completion in the study protocol (attendance at appointments).

\section{Interventions}

Our aim was to investigate the efficacy of baclofen in ALD including a low dose (30 mg/day as per Morley et al. ${ }^{12}$ and a higher dose). For this trial, the medication was sourced locally in Australia whereby baclofen is provided in either $10 \mathrm{mg}$ or $25 \mathrm{mg}$ tablets. Thus, to match the three tablets per day required for the $30 \mathrm{mg}$ dose, we chose $75 \mathrm{mg}(3 \times 25 \mathrm{mg})$ as our high dose.

Individuals read and signed the informed consent before being randomised. Randomised participants received upward and downward titrations of medication for the 84 days of treatment. Specifically, participants took a capsule of $10 \mathrm{mg}$ or $25 \mathrm{mg}$ : $1 \times$ day for the first 2 days, $2 \times$ day on days $3-4,3 \times$ day on days $5-80,2 \times$ day on days $81-82$ and finally $1 \times$ day for the last 2 days. The placebo pills, which were identical in appearance, were also titrated upward and downward to maintain the double blind.

All participants received medical care typically available at hospital-based drug and alcohol treatment services in Sydney, Australia. All participants received one medical assessment and five follow-up medical reviews over the 12-week treatment period, held at weeks $1,3,6,9,12$. Participants were medically monitored for adverse events and prescribed the study medication at each appointment. Participants who experienced moderate side-effects had their dose reduced according to physician judgement.

In addition, all participants received brief adherence therapy delivered by research psychologists who were trained and supervised by the authors (A.B., K.C.M.). Adherence therapy is an intervention aimed at targeting problems that may affect treatment adherence such as ambivalence and misperceptions about medication ${ }^{18}$ and we have utilised this intervention in previous alcohol pharmacotherapy trials. This package comprises brief intervention and assertive reminders for appointments, supervised dosing, a daily diary and feedback regarding adherence at each visit. The intervention consisted of 4-6 sessions lasting 20-60 min. The sessions were undertaken in the out-patient clinics of the treatment sites. In the first phase, participants review their history, conceptualise any problems with medication and explore beliefs about alcohol dependence and liver disease where necessary. In the second phase, a more specific discussion focuses on symptoms, side-effects of treatment and the benefits and drawbacks of treatment. In the third phase, the need for treatment maintenance and relapse prevention is addressed. The few participants (approximately 10\%) requesting other concurrent psychosocial support (for example, usual counselling care within the out-patient site) were encouraged to defer commencement until at least week 6 of the trial.

\section{Randomisation and masking}

Participants randomly were allocated 1:1:1. Allocation was made by a computer-generated block randomisation sequence that was developed by an independent team at a neighbouring institution (National Drug and Alcohol Research Centre, University of New South Wales), and then sent to the hospital clinical trials pharmacists. Participants, clinicians and research team members were masked. The integrity of the double-blind procedure was assessed by obtaining a prediction from each client as to their allocated treatment and, in addition, a prediction from the therapist and researcher (active or placebo).

\section{Assessments}

At baseline, structured diagnostic information regarding alcohol dependence and demographic variables were gathered. Alcohol 
consumption in the previous 30 days was determined using the Timeline Followback (TLFB) alcohol consumption form ${ }^{19}$ and a daily monitoring diary used in our previous alcohol treatment studies. ${ }^{20,21}$ Clinical markers of liver injury included a structured clinical assessment for symptoms and signs of liver disease performed by a physician. Full blood count, liver tests (bilirubin, gamma glutamyltransferase (GGT), alkaline phosphatase; alanine aminotransferase (ALT); aspartate aminotransferase (AST), albumin), coagulation tests (international normalised ratio) and creatinine were tested at baseline. The Childs-Pugh score, ${ }^{22}$ Maddrey Discriminant Function ${ }^{23}$ and Modified End-Stage Liver Disease $(\mathrm{MELD})^{24}$ scores were obtained by standard clinical methods.

Severity of alcohol dependence was assessed using the Alcohol Dependence Scale (ADS), ${ }^{25}$ craving was measured by the Penn Alcohol Craving Scale (PACS), ${ }^{26}$ depression, anxiety and stress levels as measured by the Depression Anxiety Stress Scale (DASS) ${ }^{27}$ and sleep problems were assessed by the Insomnia Severity Index (ISI). ${ }^{28}$ In addition, trained interviewers conducted a structured psychiatric diagnostic interview using the Mini-International Neuropsychiatric Interview (MINI). ${ }^{29}$ The TLFB, DASS, PACS, ISI were performed at each visit (five visits following the initial baseline visit: week 1, 3, 6, 9, 12). ADS and blood tests were assessed at 12 weeks. Breath alcohol concentration was assessed at each visit to ensure assessments were not conducted during intoxication.

The validity of self-report for alcohol consumption was assessed via serum analysis for \%CDT (carbohydrate deficient transferrin) in a randomly selected $25 \%$ of participants. Adherence was assessed by self-report, pill count of the returned medication package, the daily monitoring diary and urinary analysis of baclofen levels in a randomly selected $50 \%$ of participants. A sensitive liquid chromatography mass spectrometer assay (validated over the ranges of 12.5$12500 \mathrm{ng} / \mathrm{mL}$ ) was developed for determination of baclofen and its main metabolite in human urine (6.5 minutes).

\section{Outcomes measures}

Primary outcomes were time to first lapse ( 1 standard drink where one standard drink is $10 \mathrm{~g}$ of absolute alcohol); time to relapse ( $\geq 4$ drinks for women, $\geq 5$ drinks for men); average drinks per drinking day (week-12 follow-up) and number of heavy drinking days (week12 follow-up); percentage days abstinent and percentage of patients abstinent (over the 12 week trial). Secondary outcomes were alcohol dependence severity; craving; DASS scores for depression, anxiety and stress; sleep disturbance; liver function tests; frequency of adverse events and treatment adherence.

\section{Statistical analysis}

The only previously published RCT of baclofen including patients with cirrhosis ${ }^{7}$ reported a large effect size with an abstinence rate of $71 \%$ in the baclofen group and $29 \%$ in the placebo group. The sample size was calculated with a log-rank test of the difference in lapse survival between two groups (combined baclofen groups $v$. placebo as outlined in the protocol ${ }^{7}$ ) with a power of 0.80 to detect a medium-large effect with a two-tailed a of 0.05 . The main efficacy analysis was performed on an intention-to-treat basis including all participants who took at least one dose of medication following the CONSORT guidelines. ${ }^{30}$ As previously outlined ${ }^{15}$ two planned analyses were conducted: (a) placebo $v$. baclofen (composite of the two doses), followed by (b) $30 \mathrm{mg} v$. $75 \mathrm{mg}$ to determine any dose-response effect.

Survival analyses (Kaplan-Meier estimates and log-rank test) were conducted to examine the effect of treatment on length of time to relapse and length of time to lapse. The primary outcome alcohol consumption variables were entered together into a
MANOVA. These were the percentage of days abstinent, number of heavy drinking days, average drinks per drinking day at week 12. Repeated assessments from baseline, week 6 and week 12 were analysed using mixed models (alcohol dependence severity; craving; DASS scores for depression, anxiety and stress; sleep disturbance; liver function tests). The $\chi^{2}$-test were employed for continuous and categorical variables respectively to detect any significant differences on abstinence rate, side-effect profile, 'blindedness', treatment retention and medication adherence rates. Differences between the participants with and without ALD (stratified separately at randomisation) in response to baclofen were also investigated via survival analyses for time variables lapse and relapse (stratified for ALD status) and MANOVA for alcohol consumption variables (with 'treatment', 'ALD' and the interaction term 'ALD $\times$ treatment' in a full factorial model). The predictive value of ALD severity (MELD scores) was further examined within the ALD group using Cox regression survival for time to lapse and relapse by placing 'MELD' and 'MELD $\times$ treatment' as covariates.

Regarding missing data, in the case of primary outcomes (survival and multivariate), we employed sensitivity analyses to compare the results from raw data with those from multiple imputation (with ten iterations). Raw data are presented given that analyses revealed no change between the results for raw data $v$. using multiple imputation. Mixed models were also used where possible, ${ }^{31}$ which provide overall estimates of effects by averaging over the various missing-data patterns under the assumption that missing data were missing at random. All analyses were two-tailed, with significance level at $P<0.05$. Data were analysed using SPSS 23 for Mac OSX.

\section{Results}

\section{Sample characteristics}

Of the 106 patients recruited and initially randomised, two patients were not dispensed medication because of (a) unwillingness to continue and (b) comorbid psychiatric illness. Of the remaining 104, 33 were randomised to receive placebo, 36 to receive baclofen $30 \mathrm{mg}$ and 35 to receive baclofen $75 \mathrm{mg}$ (Fig. 1). One participant was dispensed medication before violation of the protocol was detected (abstinent for a total of 28 days before enrolment). Baseline characteristics are displayed in Table 1 . There were no significant differences between treatment groups at baseline confirming successful randomisation $\left(F_{\mathbf{s}}<2.47\right)$ and no differences between baclofen (composite groups) and placebo $(n=33)\left(F_{s}<3.28\right)$. Overall, the mean age was 48 (s.d. $=10$ ) years, $29 \%$ were women, $49 \%$ unemployed, average alcohol consumption was 15.03 (s.d. $=9.87$ ) drinks per drinking day and the average length of abstinence before randomisation was 4.7 days. ALD was present in $56 \%(n=58)$ of participants and $55 \%(n=57)$ of participants were taking antidepressants at the time of enrolment. Within the ALD subgroup, patients were assessed as clinically non-cirrhotic (24\%) $(n=14)$, Childs-Pugh category A (41\%) $(n=24)$, category B $(33 \%)(n=19)$ and category C $(2 \%)$ $(n=1)$. There were no significant differences between groups for MELD or Maddrey scores (Fs $<1.62, P s>0.21)$.

\section{Participant retention and adherence to treatment}

Overall, 24 (73\%) participants randomised to placebo, 24 (67\%) randomised to baclofen $30 \mathrm{mg}$ and 25 (71\%) randomised to baclofen $75 \mathrm{mg}$ completed the study. Participants did not continue the treatment programme either because of relapse, hospital admission, severe concurrent illness (psychiatric or physical), unwillingness to continue or loss to follow-up (Fig. 1). Of the 72 participants who completed the study, 60 showed $80 \%$ adherence. Of these, 21 were randomised to placebo, 20 randomised to baclofen $30 \mathrm{mg}$ and 19 


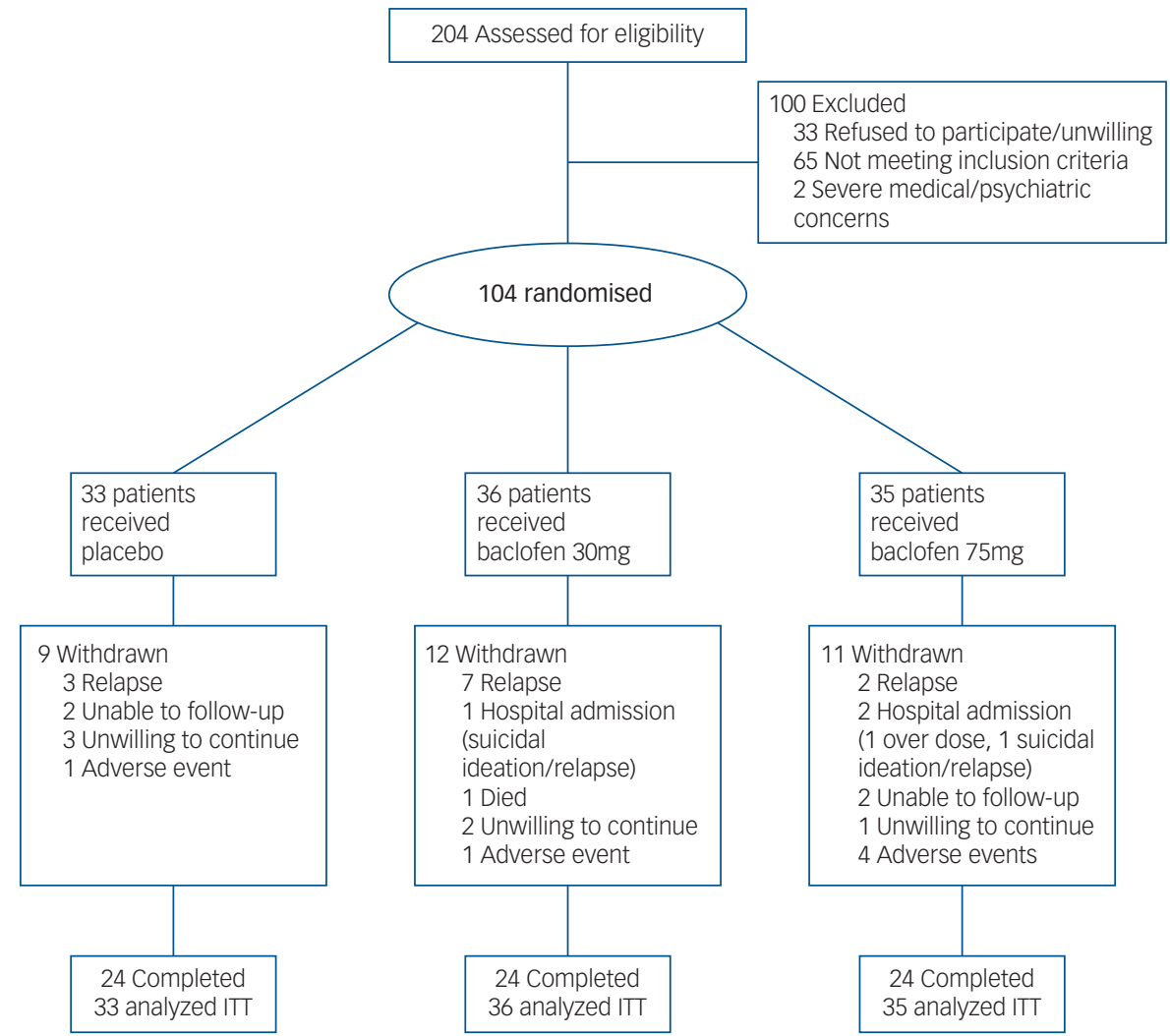

Fig. 1 Flow of participants through the randomised controlled 12-week trial of placebo, baclofen $30 \mathrm{mg}$ and baclofen $75 \mathrm{mg}$ in the treatment of alcohol dependence.

randomised to baclofen $75 \mathrm{mg}$. For all participants (intention-totreat), the mean length of time on medication was 66.03 days (s. d. $=28.25)$ for those randomised to placebo, 61.97 (s.d. $=28.45$ ) for those randomised to baclofen $30 \mathrm{mg}$ and 66.62 (s.d. $=27.48$ ) for those randomised to baclofen $75 \mathrm{mg}$. Analysis of urinary concentrations revealed $98 \%$ consistency with the self-report of pill count. Analysis of CDT\% revealed $96 \%$ consistency with selfreport of alcohol consumption. There were no significant differences between groups on retention or adherence rates $\left(\chi^{2}<0.96\right)$ or for time on medication $(F=0.26)$.

\begin{tabular}{|c|c|c|c|}
\hline Characteristic & $\begin{array}{l}\text { Placebo } \\
(n=33)\end{array}$ & Baclofen $30 \mathrm{mg}(n=36)$ & Baclofen $75 \mathrm{mg}(n=35)$ \\
\hline Age, years: mean (s.d.) & $48.18(9.91)$ & $46.25(8.81)$ & $50.71(10.59)$ \\
\hline Gender, \% women (n) & $30(10)$ & $28(10)$ & $29(10)$ \\
\hline Education, years: mean (s.d.) & $14.23(2.87)$ & $13.25(3.09)$ & $12.70(3.75)$ \\
\hline Unemployed, \% (n) & $39(13)$ & $53(19)$ & $51(18)$ \\
\hline Drinks per drinking day, ${ }^{a}$ mean (s.d.) & $14.10(7.04)$ & $17.03(12.09)$ & $13.78(9.47)$ \\
\hline Abstinence days, ${ }^{b}$ mean (s.d.) & $3.52(5.08)$ & $5.47(6.81)$ & $4.94(6.66)$ \\
\hline Years since alcohol-related problems began, mean (s.d.) & $16.26(11.55)$ & $16.86(10.44)$ & $18.74(12.33)$ \\
\hline Alcoholic liver disease, \% (n) & $55(18)$ & $56(20)$ & $57(20)$ \\
\hline Cigarette smokers, \% (n) & $64(21)$ & $75(27)$ & $60(21)$ \\
\hline Lifetime major depression, $\%^{\mathrm{C}}(\mathrm{n})$ & $61(20)$ & $61(22)$ & $60(21)$ \\
\hline Antidepressant use, \% (n) & $52(17)$ & $58(21)$ & $54(19)$ \\
\hline ADS, mean (s.d.) & $17.41(9.12)$ & $21.94(9.12)$ & $17.65(10.47)$ \\
\hline PACS craving, mean (s.d.) & $17.97(6.53)$ & $17.11(8.08)$ & $15.44(7.57)$ \\
\hline DASS depression, mean (s.d.) & $19.88(12.56)$ & $15.44(9.72)$ & $15.53(12.56)$ \\
\hline DASS anxiety, mean (s.d.) & $10.56(8.58)$ & $14.72(10.00)$ & $11.82(8.92)$ \\
\hline DASS stress, mean (s.d.) & $18.31(10.46)$ & $18.67(8.46)$ & $17.35(10.52)$ \\
\hline ISI, mean (s.d.) & $15.72(6.40)$ & $14.56(6.68)$ & $12.76(6.47)$ \\
\hline GGT, mean (s.d.) & $236.04(391.22)$ & $221.26(216.83)$ & $239.00(472.69)$ \\
\hline ALT, mean (s.d.) & $62.77(51.98)$ & $52.39(26.84)$ & $49.84(36.74)$ \\
\hline AST, mean (s.d.) & $65.58(57.03)$ & $61.83(37.81)$ & $55.72(48.03)$ \\
\hline
\end{tabular}




\section{Safety and tolerability}

The profile of side-effects reported by participants is shown in Table 2. There were significant treatment differences for drowsiness/sedation and shortness of breath (likelihood ratio: $\chi^{2}>6.20$, $\left.P_{s}<0.05\right)$. Patients randomised to baclofen $75 \mathrm{mg}$ were significantly more likely to report drowsiness/sedation (likelihood ratio: $\chi^{2}=$ 9.53, $P<0.001)$ and shortness of breath compared with those randomised to $30 \mathrm{mg}$ (likelihood ratio: $\chi^{2}=7.18, P<0.05$ ). There were four serious adverse events as follows: one death (baclofen $30 \mathrm{mg}$ ) that was attributed to be unrelated to study medication (liver cancer present on study entry); two admissions to hospital because of suicidal ideation and alcohol intoxication that were judged to be possibly related to study medication; one overdose (baclofen $75 \mathrm{mg}$ group, without ALD) resulting in presentation to the emergency department with depressed level of consciousness (vital signs within normal limits) that was judged to be related to study medication. The exact quantity of tablets consumed could not be accurately determined but was estimated to be no more than $23(800 \mathrm{mg})$ and consumed while intoxicated. The patient was discharged within $48 \mathrm{~h}$.

In the baclofen $75 \mathrm{mg}$ group, 20\% (7) dropped out because of adverse events or as a result of a serious adverse event, compared to $6 \%$ (2) in the $30 \mathrm{mg}$ group and $3 \%$ (1) in the placebo group (likelihood ratio: $\left.\chi^{2}=6.67, P<0.05\right)$. With regards to tolerability, in the $75 \mathrm{mg}$ group, $11 \%$ (4) ceased taking the medication citing sideeffects compared with $3 \%$ (1) in the $30 \mathrm{mg}$ group and $3 \%$ (1) in the placebo group (likelihood ratio: $\chi^{2}=3.11, P=0.21$ ). Three patients in the $75 \mathrm{mg}$ group reduced the dose because of sideeffects (one dropped down to $25 \mathrm{mg}$ /day and two dropped to 50 $\mathrm{mg} /$ day) but no patients in the other two groups reduced their dose.

\section{Integrity of the double blind}

Overall, clinicians were able to differentiate active correctly from placebo treatment in $57 \%$ of cases. Researchers were able to differentiate active correctly from placebo treatment in $59 \%$ of cases. Of all participants, $60 \%$ were able to differentiate active correctly from placebo treatment whereas $22 \%$ of placebo participants and $79 \%$ of active participants correctly guessed and this was not significant $\left(\chi_{2,100}^{2}=0.01, P=0.97\right)$.

\section{Main efficacy results}

Data regarding alcohol consumption at follow-up was unable to be obtained for 11 participants (11\%). At week 12, drinking data for relapse and lapse was available for $89 \%$ of participants. Survival analyses for the time to first lapse and first relapse for each dose are depicted in Fig. 2(a) and 2(b), respectively.

Survival analyses revealed significant treatment effects (placebo $v$. baclofen composite) for the number of days to first lapse (log rank: $\left.\chi^{2}=6.44, P<0.05, d=0.56\right)$ and the number of days to

Table 2 Side-effect profile of participants treated with either baclofen $30 \mathrm{mg}, 75 \mathrm{mg}$ or placebo (intention-to-treat)

\begin{tabular}{|c|c|c|c|}
\hline Clinical event & $\begin{array}{l}\text { Placebo, } \\
n(\%)\end{array}$ & $\begin{array}{l}\text { Baclofen } \\
30 \mathrm{mg}, n(\%)\end{array}$ & $\begin{array}{l}\text { Baclofen } \\
75 \mathrm{mg}, n(\%)\end{array}$ \\
\hline Sedation or drowsiness* & $10(30)$ & $7(19)$ & $18(51)$ \\
\hline Dizziness & $3(9)$ & $2(6)$ & $7(20)$ \\
\hline Skin rash/itching & $5(15)$ & $5(14)$ & $1(3)$ \\
\hline Constipation & $2(6)$ & $3(8)$ & $3(9)$ \\
\hline Shortness of breath* & $1(3)$ & $0(0)$ & $4(11)$ \\
\hline Dry mouth & $1(3)$ & $3(8)$ & $1(3)$ \\
\hline Urination problems & $0(0)$ & $1(3)$ & $2(6)$ \\
\hline Sleep disturbances & $2(6)$ & $0(0)$ & $0(0)$ \\
\hline \multicolumn{4}{|c|}{$\begin{array}{l}\text { In the } 75 \mathrm{mg} \text { group, } 9 \% \text { (3) of patients reduced the dose because of intolerability ( } 1 \\
\text { patient } 25 \mathrm{mg} / \text { day and two patients } 50 \mathrm{mg} / \text { day). } \\
\star P<0.05 \text {, significant difference between baclofen } 75 \mathrm{mg} \text { and baclofen } 30 \mathrm{mg} \text {. }\end{array}$} \\
\hline
\end{tabular}

relapse (log rank: $\chi^{2}=4.62, P<0.05, d=0.52$ ). There was no significant treatment effect for rate of participants abstinent over the 12week trial $\left(\chi^{2}=2.12, P=0.15\right)$. MANOVA revealed a significant overall treatment effect attributed to alcohol consumption (Wilks multivariate test of significance; effect of treatment: $F_{3,68}=3.29$, $P<0.05)$ whereby there was a significant between-participant effect for percentage days abstinent $\left(F_{2,69}=7.42, P<0.01\right)$ but not for the other alcohol consumption outcome variables $(F s<1.10)$ (see Table 3). The number needed to treat based on the criterion of continuous abstinence was 8.3 for baclofen (composite of $30 \mathrm{mg}$ and 75 $\mathrm{mg}$ groups). Mixed models revealed a significant effect of time for alcohol dependence, craving, depression, anxiety and sleep

(a)

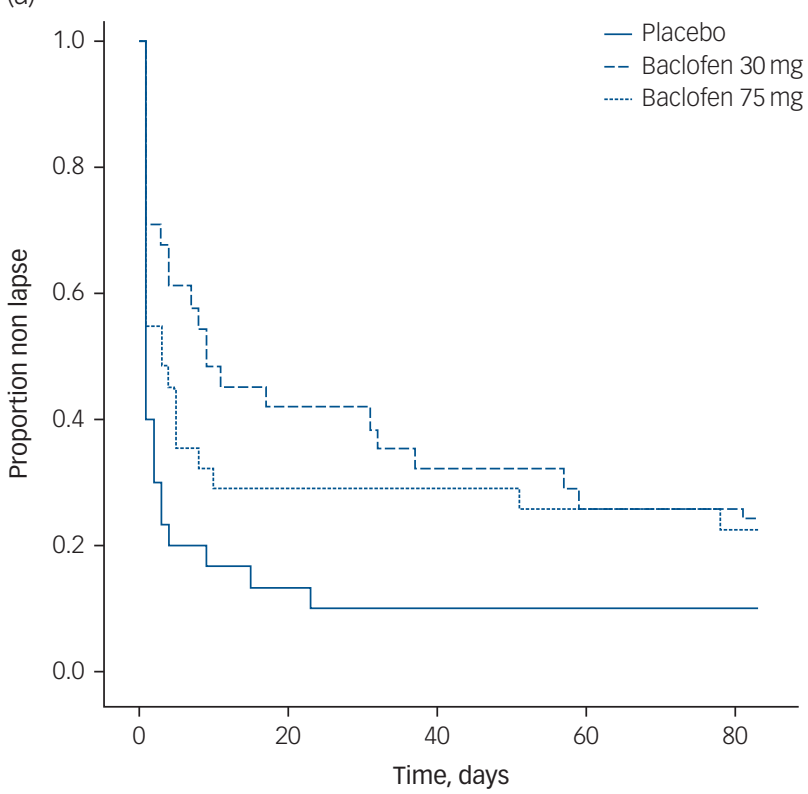

(b)

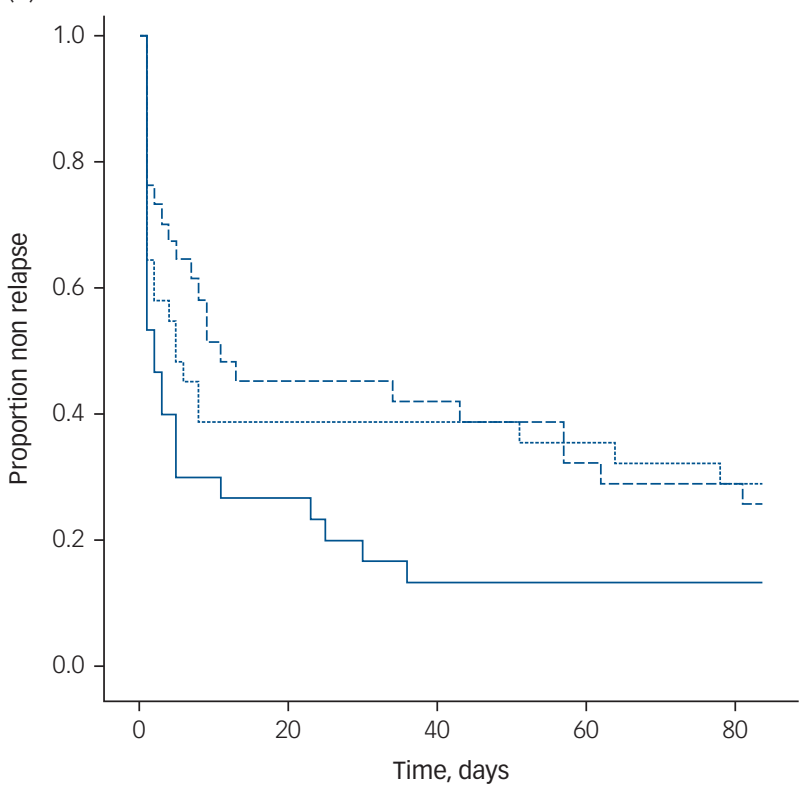

Fig. 2 Survival curve of (a) time to lapse and (b) time to relapse for participants randomised to either placebo, baclofen $30 \mathrm{mg}$ or baclofen $75 \mathrm{mg}$ for 12 weeks.

Intention-to-treat analysis. Significant treatment effects emerged between placebo and baclofen (combined doses) for time to lapse (log rank: $\left.\chi^{2}=6.44, P<0.05\right)$ and time to relapse (log rank: $\chi^{2}=4.62, P<0.05$ ) but not between baclofen $30 \mathrm{mg}$ and baclofen $75 \mathrm{mg}$ (log rank: $\left.\chi^{2} \mathrm{~S}<0.42, P S>0.52\right)$. 
$\left(F s<15.87, P_{s}<0.0001\right)$ but there were no significant time $\times$ medication effects $\left(F_{s}<2.20\right.$, Ps $\left.>0.11\right)$ suggesting that these reductions were not because of baclofen treatment. Mixed model analysis of repeated measures revealed significant reductions in serum levels of GGT, ALT or AST over time $\left(F_{\mathrm{s}}>3.76, P_{\mathrm{s}}<0.05\right)$, but not for treatment or treatment $\times$ time interaction $(F s<0.40$, Ps $>0.67)$.

With regards to between-dose comparisons for baclofen, there were no significant differences between the $30 \mathrm{mg} / \mathrm{day} v$. the $75 \mathrm{mg} /$ day dose for the number of days to first lapse (log rank: $\chi^{2}=0.42, P=0.52$ ) or the number of days to relapse (log rank: $\left.\chi^{2}=0.05, P=0.83\right)$. MANOVA did not reveal a significant overall treatment effect between doses attributed to alcohol consumption (Wilks multivariate test of significance: $F_{3,44}=1.13$, $P<0.35)$. The number needed to treat based on the criterion of continuous abstinence was 9.1 for $30 \mathrm{mg} /$ day and 7.7 for $75 \mathrm{mg} /$ day doses of baclofen.

\section{ALD v. non-ALD}

There were significant baseline characteristics between the ALD $v$. non-ALD subgroups on age $\left(F_{2,102}=10.04, P<0.05\right)$, education $\left(F_{2,102}=5.69, P<0.05\right)$, employment $\left(\chi^{2}=28.37, P<0.0001\right)$ standard drinks per drinking day $\left(F_{2,102}=13.61, P<0.001\right)$, GGT $\left(F_{2,102}=11.25, P<0.01\right)$, ALT $\left(F_{2,102}=8.74, P<0.01\right)$ and AST $\left(F_{2,102}=33.00, P<0.001\right)$ (see Table 4$)$. There were no significant differences between baseline characteristics between baclofen (composite groups) and placebo ( $P \mathrm{~s}>0.15)$ within the ALD subgroup, confirming successful randomisation (within stratification). In the ALD subgroup, there were significant differences between baclofen (two dose group composite) and placebo for the number of days to first lapse (log rank: $\left.\chi^{2}=5.58, P<0.05\right)$ and relapse (log rank: $\chi^{2}=$ 5.02, $P<0.05$ ) but not for the non-ALD subgroup (log rank: $\chi^{2} s<$ $2.40, P \mathrm{~s}>0.05)$. MANOVA revealed no significant overall effect for treatment $\times$ ALD (Wilks $F_{3,66}=0.41, \quad P>0.05$; observed power 0.13 ) for alcohol consumption variables. There were no differences between the ALD and non-ALD subgroups for frequency of each adverse event $\left(\chi^{2} s<2.91, P s>0.05\right)$, stopping medication because of side-effects $\left(\chi^{2}=0.31, P \mathrm{~s}>0.05 ; 4 \%(n=2)\right.$ and $7 \%(n=4)$ for nonALD and ALD subgroups, respectively) or serious adverse events $\left(\chi^{2}=0.06, P>0.05\right)$. Within the ALD subgroup, time to lapse and relapse was not significantly predicted by MELD or MELD $\times$ treatment $(P \mathrm{~s}>0.62) .3$

\section{Discussion}

\section{Main findings and comparison with other studies}

The current results provide evidence that low-medium dose baclofen treatment can have significant benefits on drinking outcomes relative to placebo in patients with liver disease. The intention-totreat analyses indicated that there was a significant difference for time to lapse, time to relapse and percentage days abstinent between the treatment groups. These findings are consistent with several double-blind RCTs demonstrating efficacy of baclofen to reduce alcohol consumption in several countries such as Italy $^{7}$ and Germany ${ }^{14}$ and also consistent with open-label studies. ${ }^{32}$ It is relevant to note that while the effect size for time to lapse is medium $(d=0.56)$, the number needed to treat based on the criterion of continuous abstinence is still high from a clinical perspective (8.3). We did not observe any significant improvements on liver function tests which may be because of the low rates of abstinence overall. Baclofen did not improve measures of alcohol dependence, craving depression, sleep or anxiety.

The positive outcomes reported in the current study are inconsistent with several double blind RCTs that have failed to demonstrate any efficacy of baclofen relative to placebo in patients without ALD. ${ }^{9,10,13,33}$ However, there are some important differences in the protocol of these trials. First, the level of concomitant psychotherapy is likely to be an important factor in determining treatment response. The negative trial conducted by Beraha et $a l^{13}$ included comprehensive motivational enhancement therapy and the negative trial by Ponizovsky et $a l^{10}$ included weekly intensive individual and group cognitive-behavioural-based therapy. In

\begin{tabular}{|c|c|c|c|}
\hline Outcome & $\begin{array}{l}\text { Placebo } \\
(n=33)\end{array}$ & Baclofen $30 \mathrm{mg}(n=36)$ & Baclofen $75 \mathrm{mg}(n=35)$ \\
\hline \multicolumn{4}{|l|}{ Alcohol consumption measures } \\
\hline Time to first lapse, days:* mean (SEM) & $11.10(4.52)$ & $31.16(6.18)$ & $24.97(6.37)$ \\
\hline Time to first relapse, days:* mean (SEM) & $16.67(5.11)$ & $34.97(6.40)$ & $32.26(6.80)$ \\
\hline Percentage days abstinent, mean (SEM) ${ }^{\mathrm{a}}$, & $43.35(7.60)$ & $68.54(5.90)$ & $64.56(7.69)$ \\
\hline Average drinks per drinking day, ${ }^{b, c}$ mean (s.d.) & $7.50(6.46)$ & $8.82(10.38)$ & $4.67(4.86)$ \\
\hline Number of heavy drinking days, d,e mean (s.d.) & $2.46(2.77)$ & $2.28(2.89)$ & $1.65(2.48)$ \\
\hline Abstinencef,$\%$ & $10(3)$ & $21(7)$ & $23(7)$ \\
\hline \multicolumn{4}{|l|}{ Alcohol dependence measures } \\
\hline Alcohol Dependence Scale score, mean (s.d.) & $12.61(10.20)$ & $14.00(10.51)$ & $12.09(10.75)$ \\
\hline PACS score, mean (s.d.) & $16.00(7.57)$ & $9.26(8.14)$ & $12.13(7.61)$ \\
\hline \multicolumn{4}{|l|}{ Psychological measures } \\
\hline DASS depression, mean (s.d.) & $14.00(15.74)$ & $10.17(11.09)$ & $11.83(10.11)$ \\
\hline DASS anxiety, mean (s.d.) & $9.91(11.40)$ & $7.65(9.72)$ & $7.83(7.55)$ \\
\hline DASS stress, mean (s.d.) & $15.73(13.54)$ & $11.39(9.37)$ & $12.52(9.42)$ \\
\hline ISI, mean (s.d.) & $11.08(8.94)$ & $8.35(6.89)$ & $10.39(6.85)$ \\
\hline \multicolumn{4}{|l|}{ Liver function tests } \\
\hline GGT, mean (s.d.) & $196.07(377.72)$ & 267.75 (345.94) & $138.40(302.53)$ \\
\hline ALT, mean (s.d.) & $50.73(40.81)$ & $64.08(47.04)$ & $52.87(52.65)$ \\
\hline AST, mean (s.d.) & $66.67(82.98)$ & $76.91(85.55)$ & $60.73(54.85)$ \\
\hline \multicolumn{4}{|c|}{$\begin{array}{l}\text { PACS, Penn Alcohol Craving Scale; DASS, Depression, Anxiety and Stress scale; ISI, Insomnia Severity Index. GGT, gamma glutamyltransferase; ALT, alanine aminotransferase; AST, aspartate } \\
\text { aminotransferase. } \\
\text { a. Over } 84 \text { days of trial. } \\
\text { b. Drinks is equal to standard drink ( } 10 \mathrm{mg} \text { ethanol). } \\
\text { C. At week } 12 \text {-follow-up. } \\
\text { d. Defined as } \geq 4 \text { drinks for women and } \geq 5 \text { drinks for men. } \\
\text { e. Per week at week- } 12 \text { follow-up. } \\
\text { f. As per complete data ( } \mathrm{n} \text { : placebo }=31 \text {, baclofen } 30 \mathrm{mg}=33 \text {, baclofen } 75 \mathrm{mg}=31 \text { ). } \\
\star P<0.05 \text {, comparing baclofen (composite of } 30 \mathrm{mg} \text { and } 75 \mathrm{mg} \text { ) } \mathrm{V} \text {. placebo. }\end{array}$} \\
\hline
\end{tabular}


Table 4 Intention-to-treat: baseline characteristics of the non-ALD v. ALD subgroups

\begin{tabular}{|c|c|c|}
\hline Characteristic & $\begin{array}{l}\text { Non-ALD } \\
(n=46)\end{array}$ & $\operatorname{ALD}(n=58)$ \\
\hline Age, year: * mean (s.d.) & $45.07(10.26)$ & $50.98(8.78)$ \\
\hline Gender, \% women & $35(16)$ & $24(14)$ \\
\hline Education, years:* mean (s.d.) & $14.22(3.04)$ & $12.63(3.36)$ \\
\hline Unemployed, \%* & 20 (9) & $71(41)$ \\
\hline Drinks per drinking day, ${ }^{a, \star}$ mean (s.d.) & $11.20(5.51)$ & $18.05(11.44)$ \\
\hline Abstinence days, ${ }^{\mathrm{b}}$ mean (s.d.) & $2.72(5.10)$ & $6.22(6.70)$ \\
\hline $\begin{array}{l}\text { Years since alcohol-related problems } \\
\text { began, mean (s.d.) }\end{array}$ & $16.50(11.45)$ & $17.98(11.40)$ \\
\hline Cigarette smokers, \% & 74 (34) & $60(35)$ \\
\hline 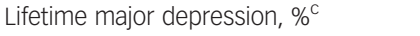 & $52(24)$ & 67 (39) \\
\hline Antidepressant use, \% & $63(29)$ & $48(28)$ \\
\hline ADS, mean (s.d.) & $18.53(8.25)$ & $19.53(10.81)$ \\
\hline PACS craving, mean (s.d.) & $18.09(5.88)$ & $15.82(8.41)$ \\
\hline DASS depression, mean (s.d.) & $16.31(11.00)$ & $17.30(11.49)$ \\
\hline DASS anxiety, mean (s.d.) & $10.67(9.17)$ & $13.86(9.23)$ \\
\hline DASS stress, mean (s.d.) & $17.91(10.52)$ & $18.28(9.17)$ \\
\hline ISI, mean (s.d.) & $13.29(6.75)$ & $15.14(6.37)$ \\
\hline GGT,* mean (s.d.) & $92.03(112.18)$ & $365.47(476.61)$ \\
\hline$A L T,{ }^{*}$ mean (s.d.) & $41.67(29.12)$ & $67.97(45.23)$ \\
\hline AST, ${ }^{*}$ mean (s.d.) & $33.53(17.15)$ & $87.18(53.49)$ \\
\hline \multicolumn{3}{|c|}{$\begin{array}{l}\text { ADS, Alcohol Dependence Severity Scale; PACS, Penn Alcohol Craving Scale; DASS, } \\
\text { Depression, Anxiety and Stress scale; ISI, Insomnia Severity Index; GGT, gamma gluta- } \\
\text { myltransferase; ALI, alanine aminotransferase, } \text { AST: aspartate aminotransferase. } \\
\text { a. During the } 30 \text { days preceding the first day of the study, based on the Timeline } \\
\text { Followback method. } \\
\text { b. Before enrolment. } \\
\text { c. Past, current or recurrent major depression as measured by the Mini-Neuropsychiatric } \\
\text { Diagnostic Interview. } \\
\text { * } P<0.05 \text {. }\end{array}$} \\
\hline
\end{tabular}

contrast, the participants in positive studies received only brief supportive counselling ${ }^{7}$ and brief medical management. ${ }^{14}$ In the current study, participants received brief adherence therapy delivered in conjunction with the research appointment. High ceiling effects in the placebo group of clinical trials with comprehensive psychosocial interventions may negate the detection of baclofen efficacy, suggesting that baclofen treatment would perhaps not be necessary in the presence of other intensive psychosocial options.

Furthermore, varying levels of drinking characteristics may play a role in explaining inconsistencies across studies. For example, the sample in the negative Garbutt $e a^{33}$ trial and Reynaud et al ${ }^{9}$ trial had lower baseline drinking levels (seven and nine drinks per drinking day). A further double-blind RCT did not report any efficacy of adjunctive baclofen to manual-guided counselling in veterans with hepatitis $\mathrm{C}$, consistent with our hypothesis, the participants in this latter sample were drinking seven standard drinks per day. ${ }^{34}$ Whereas our current sample were drinking 15 drinks per drinking day and the positive Muller et $a^{14}$ study were drinking 20 drinks per day. To this degree, we report marked differences with respect to baseline drinking levels (11 and 18 standard drinks, respectively) between our non-ALD and ALD subgroups and our stratification analysis revealed that the treatment effect of baclofen was stronger in the ALD subgroup for delaying time to lapse and relapse. However, we did not find any significant interaction effect of ALD $\times$ treatment on drinking outcomes although this may be because of a lack of power to perform the full factorial model in this sample. Patients with ALD have lower cortical GABA levels ${ }^{35}$ and have an extended history of heavy drinking ${ }^{36}$ similar to our current results. Further, Addolorato et $a l^{7}$ demonstrated increasing effectiveness of baclofen on abstinence with greater severity of ALD and indeed, observational studies are increasingly supporting the use of baclofen to reduce drinking outcomes and improve liver function in patients with ALD. ${ }^{37,38}$

It may be that individual alterations in GABA receptor activity that occur following chronic drinking predict response to GABA- ergic agents such as baclofen. Chick \& $\mathrm{Nutt}^{39}$ have previously highlighted baclofen to be a potential agent for a substitution therapy strategy in the treatment for alcohol dependence because of similarities with the neuropharmacological actions of alcohol. In light of this, baclofen has been demonstrated in human laboratory studies to have biphasic effects on alcohol by increasing stimulation and the feeling of intoxication but also sedation, ${ }^{40,41}$ leading the authors to conclude that the efficacy of baclofen is more likely to be because of alcohol substitution effects rather than antireinforcing properties. It is possible that patients who are alcohol dependent with liver disease drinking heavily before commencement of pharmacotherapy may be the appropriate clinical subgroup for substitution therapy with baclofen given otherwise severe and imminent health risk of heavy drinking that is highly costly to the community.

\section{Safety and tolerability}

With regards to safety and tolerability, although the majority of patients tolerated baclofen, patients randomised to the $75 \mathrm{mg}$ dose of baclofen reported significantly more sedation compared with the $30 \mathrm{mg}$ dose. In addition, there were several serious adverse events, with one patient randomised to the $75 \mathrm{mg}$ dose taking an overdose of baclofen. It is well documented that baclofen is highly toxic in overdose. ${ }^{42}$ High-dose baclofen has been associated with a range of adverse events including episodes of sedation after concurrent alcohol consumption. ${ }^{43}$ Indeed, case studies suggest that patients with some comorbid psychiatric conditions (such as personality disorders, bipolar disorder) or comorbid substance use are unsuitable for baclofen. ${ }^{44}$ Future research may confirm that patients with suicidal ideation or a history of overdose are more likely to experience a serious adverse response to baclofen.

\section{Implications}

In conclusion, the current trial demonstrated that baclofen (30-75 $\mathrm{mg}$ /day) is an effective treatment in people with alcohol dependence with and without liver disease drinking at an average level of 15 drinks per drinking day. However, our safety data raise some doubt about the use of higher doses of baclofen for patients in the community and suggest that prescribing should be limited to specialist services where careful treatment supervision is provided. This work is an important example of multidisciplinary efforts and so carries an important value from a clinical and public health stand point. Future research on the factors that influence the suitability of alcohol pharmacotherapy in certain subgroups is essential for the development of effective treatment options for alcohol dependence.

Kirsten C. Morley B Psych, MPH, PhD, NHMRC Centre of Research Excellence in Mental Health and Substance Use, $\mathrm{Central}$ Clinical Schol Syd Sydney, New South Wales, Australia; Andrew Baillie, M Clin Psych, PhD, MAPS, FCCLP, NHMRC Centre of Research Excellence in Mental Health and Substance Use, Department of Psychology, Macquarie University, New South Wales, Australia; Isabel Fraser, M Clin Psych, Ainsley Furneaux-Bate, B Psych, NHMRC Centre of Research Excellence in Mental Health and Substance Use, Central Clinical School, Sydney Medical School, University of Sydney, New South Wales, Australia; Glenys Dore, MB ChB, FRANZCP, FAChA, Herbert St Alcohol Clinic, Royal North Shore Hospital, Sydney, New South Wales, Australia; Michael Roberts, PhD, DSC, MBA, FACP, FAAHMS, School of Pharmacy and Medical Sciences, University of South Australia, Adelaide and Therapeutics Research Centre, Diamantina Institute, The University of Queensland, Translational Research Institute, Brisbane, Australia; Ahmed Abdalla, B MedSci, School of Pharmacy and Medical Sciences, University of South Australia, Adelaide, Australia; Nghi Phung, MBBS, PhD, FRACP, FAChAM, Centre for Addiction Medicine, Westmead Hospital Sydney, New South Wales, Australia; Paul S. Haber, MBBS, BMedSC, MD, FRACP, FAChAM, Drug Health Services, Royal Prince Alfred Hospital, New South Wales, Australia

Correspondence: Kirsten C. Morley, Discipline of Addiction Medicine, Central Clinical School, Sydney Medical School, University of Sydney, 2006, New South Wales, Australia. Email: kirsten.morley@sydney.edu.au

First received 7 Nov 2017, accepted 10 Jan 2018 


\section{Funding}

This study was supported by a grant from the National Health and Medical Research Council of Australia (P.S.H., A.B., K.C.M.).

\section{Acknowledgements}

We thank our clinical colleagues who assisted with recruitment and treatment at the participating centres.

\section{References}

1 World Health Organization. Global Information System on Alcohol and Health WHO, 2015

2 Bosetti C, Levi F, Lucchini F, Zatonski WA, Negri E, La VC. Worldwide mortality from cirrhosis: an update to 2002. J Hepatol 2007; 46: 827-39.

3 Tilg H, Day CP. Management strategies in alcoholic liver disease. Nat Clin Pract Gastroenterol Hepatol 2007; 4: 24-34.

4 Addolorato G, Mirijello A, Leggio L, Ferrulli A, Landolfi R. Management of alcohol dependence in patients with liver disease. CNS Drugs 2013; 27: 287-99.

5 Colombo G, Addolorato G, Agabio R, Carai MA, Pibiri F, Serra S, et al. Role of $\mathrm{GABA}(\mathrm{B})$ receptor in alcohol dependence: reducing effect of baclofen on alcohol intake and alcohol motivational properties in rats and amelioration of alcohol withdrawal syndrome and alcohol craving in human alcoholics. Neurotox Res 2004; 6: 403-14.

6 Maccioni P, Colombo G. Role of the GABA(B) receptor in alcohol-seeking and drinking behavior. Alcohol 2009; 43: 555-8.

7 Addolorato G, Leggio L, Ferrulli A, Cardone S, Vonghia L, Mirijello A, et al. Effectiveness and safety of baclofen for maintenance of alcohol abstinence in alcohol-dependent patients with liver cirrhosis: randomised, double-blind controlled study. Lancet 2007; 370: 1915-22.

8 Chaignot C, Weill A, Ricordeau P, Alla F. Use in france of baclofen for alcohol dependence from 2007 to 2013: cohort study based on the databases SNIIRAM and PMSI. Therapie 2015; 70: 443-53.

9 Reynaud M, Aubin HJ, Trinquet F, Zakine B, Dano C, Dematteis M, et al. A randomized, placebo-controlled study of high-dose baclofen in alcohol-dependent patients-the ALPADIR study. Alcohol Alcohol 2017; 52: 439-46.

10 Ponizovsky AM, Rosca P, Aronovich E, Weizman A, Grinshpoon A. Baclofen as add-on to standard psychosocial treatment for alcohol dependence: a randomized, double-blind, placebo-controlled trial with 1 year follow-up. J Subst Abuse Treat 2015; 52: 24-30.

11 Addolorato G, Caputo F, Capristo E, Domenicali M, Bernardi M, Janiri L, et al. Baclofen efficacy in reducing alcohol craving and intake: a preliminary doubleblind randomised controlled study. Alcohol Alcohol 2002; 37: 504-8.

12 Morley KC, Baillie A, Leung S, Addolorato G, Leggio L, Haber PS. Baclofen for the treatment of alcohol dependence and possible role of comorbid anxiety. Alcohol Alcohol 2014; 49: 654-60.

13 Beraha EM, Salemink E, Goudriaan AE, Bakker A, de Jong D, Smits N, et al. Efficacy and safety of high-dose baclofen for the treatment of alcohol dependence: a multicentre, randomised, double-blind controlled trial. Eur Neuropsychopharmacol 2016; 26: 1950-9.

14 Muller CA, Geisel O, Pelz P, Higl V, Kruger J, Stickel A, et al. High-dose baclofen for the treatment of alcohol dependence (BACLAD study): a randomized, placebo-controlled trial. Eur Neuropsychopharmacol 2015; 25: 1167-77.

15 Morley KC, Leung S, Baillie A, Haber PS. The efficacy and biobehavioural basis of baclofen in the treatment of alcoholic liver disease (BaCALD): study protocol for a randomised controlled trial. Contemp Clin Trials 2013; 36: 348-55.

16 World Health Organization. The ICD-10 Classification of Mental and Behavioural Disorders: Clinical Descriptions and Diagnostic Guidelines. WHO, 1992.

17 Sullivan JT, Sykora K, Schneiderman J, Naranjo CA, Sellers EM. Assessment of alcohol withdrawal: the revised clinical institute withdrawal assessment for alcohol scale (CIWA-Ar). Br J Addict 1989; 84: 1353-7.

18 Teesson M, Sannibale C, Reid SC, Proudfoot H, Gournay K, Haber P. Manual for Compliance Therapy in Alcohol Pharmacotherapy. NDARC Technical Report 157. NDARC, 2003.

19 Sobell LC, Maisto SA, Sobell MB, Cooper A. Reliability of alcohol abusers' selfreports of drinking behavior. Behav Res Ther 1979; 17: 157-60.
20 Morley KC, Teesson M, Reid SC, Sannibale C, Thomson C, Phung N, et al. Naltrexone versus acamprosate in the treatment of alcohol dependence: a multi-centre, randomized, double-blind, placebo-controlled trial. Addiction 2006; 101: 1451-62.

21 Morley KC, Baillie A, Leung S, Sannibale C, Teesson M, Haber PS. Is specialized integrated treatment for comorbid anxiety, depression and alcohol dependence better than treatment as usual in a public hospital setting? Alcohol Alcohol 2016; 51: 402-9.

22 Child CG, Turcotte JG. Surgery and portal hypertension. In The Liver and Portal Hypertension (ed CG Child): 50-64. Saunders, 1964

23 Maddrey WC, Boitnott JK, Bedine MS, Weber FL, Mezey E, White RI. Corticosteroid therapy of alcoholic hepatitis. Gastroenterology 1978; 75 (2): 193-9.

24 Kamath PS, Kim WR. The model for end-stage liver disease (MELD). Hepatology 2007; 45 (3): 797-805.

25 Skinner HA, Allen BA. Alcohol dependence syndrome: measurement and validation. J Abnorm Psychol 1982; 91: 199-209.

26 Flannery B, Volpicelli J, Pettinati H. Psychometric properties of the Penn Alcohol Craving Scale. Alcohol Clin Exp Res 1999; 23: 1289-95.

27 Lovibond PF, Lovibond SH. Manual for the Depression Anxiety Stress Scales. Psychology Foundation of Australia, 1995.

28 Bastien $\mathrm{CH}$, Vallieres A, Morin CM. Validation of the Insomnia Severity Index as an outcome measure for insomnia research. Sleep Med 2001; 2: 297-307.

29 Sheehan DV, Lecrubier $Y$, Sheehan $\mathrm{KH}$, Amorim P, Janavs J, Weiller E, et al. The Mini-International Neuropsychiatric Interview (M.I.N.I.): the development and validation of a structured diagnostic psychiatric interview for DSM-IV and ICD-10. J Clin Psychiatry 1998; 59 (suppl 20): 22-33.

30 Schulz KF, Altman DG, Moher D. CONSORT 2010 Statement: updated guidelines for reporting parallel group randomised trials. Br Med J 2010; 340: $\mathrm{C332}$

31 Hallgren KA, Witkiewitz K. Missing data in alcohol clinical trials: a comparison of methods. Alcohol Clin Exp Res 2013; 37: 2152-60.

32 Gupta M, Verma P, Rastogi R, Arora S, Elwadhi D. Randomized open-label trial of baclofen for relapse prevention in alcohol dependence. Am J Drug Alcohol Abuse 2017; 43: 324-31.

33 Garbutt JC, Kampov-Polevoy AB, Gallop R, Kalkajuhl L, Flannery BA. Efficacy and safety of baclofen for alcohol dependence: a randomized, double-blind, placebo-controlled trial. Alcohol Clin Exp Res 2012; 34: 1849-57.

34 Hauser P, Fuller B, Ho SB, Thuras P, Kern S, Dieperink E. The safety and efficacy of baclofen to reduce alcohol use in veterans with chronic hepatitis $\mathrm{C}$ : a randomized controlled trial. Addiction 2017; 112: 1173-83.

35 Behar KL, Rothman DL, Petersen KF, Hooten M, Delaney R, Petroff OA, et al. Preliminary evidence of low cortical GABA levels in localized 1H-MR spectra of alcohol-dependent and hepatic encephalopathy patients. Am J Psychiatry 1999; 156: 952-4.

36 Leggio L, Lee MR. Treatment of Alcohol Use Disorder in Patients with Alcoholic Liver Disease. Am J Med 2017; 130: 124-34.

37 Owens L, Thompson A, Rose A, Gilmore I, Pirmohamed M, Richardson P. A prospective cohort study examining the effectiveness of baclofen in the maintenance of abstinence in alcohol use disorder patients attending a joint liver and alcohol treatment clinic. Alcohol 2017; 62: 11-5.

38 Yamini D, Lee SH, Avanesyan A, Walter M, Runyon B. Utilization of baclofen in maintenance of alcohol abstinence in patients with alcohol dependence and alcoholic hepatitis with or without cirrhosis. Alcohol Alcohol 2014; 49: 453-6.

39 Chick J, Nutt DJ. Substitution therapy for alcoholism: time for a reappraisal? J Psychopharmacol 2012; 26: 205-12.

40 Farokhnia M, Schwandt ML, Lee MR, Bollinger JW, Farinelli LA, Amodio JP, et al. Biobehavioral effects of baclofen in anxious alcohol-dependent individuals: a randomized, double-blind, placebo-controlled, laboratory study. Trans/ Psychiatry 2017; 7: e1108

41 Leggio L, Zywiak WH, McGeary JE, Edwards S, Fricchione SR, Shoaff JR, et al. A human laboratory pilot study with baclofen in alcoholic individuals. Pharmacol Biochem Behav 2013; 103: 784-91.

42 Leung NY, Whyte IM, Isbister GK. Baclofen overdose: defining the spectrum of toxicity. Emerg Med Australas 2006; 18: 77-82.

43 Rolland B, Labreuche J, Duhamel A, Deheul S, Gautier S, Auffret M, et al. Baclofen for alcohol dependence: relationships between baclofen and alcoho dosing and the occurrence of major sedation. Eur Neuropsychopharmacol 2015; 25: 1631-6.

44 Dore GM, Lo K, Juckes L, Bezyan S, Latt N. Clinical experience with baclofen in the management of alcohol-dependent patients with psychiatric comorbidity: a selected case series. Alcohol Alcohol 2011; 46: 714-20. 